\title{
MINERAL WATER FROM SPRING PX-6 - PHYSICO-CHEMICAL CHARACTERISTICS AND INDICATIONS FOR USE
}

\author{
Evegniya Vladeva \\ Department of Thalassotherapy, Physiotherapy, Rehabilitation, and Occupational \\ Diseases, Faculty of Public Health, Medical University of Varna
}

\begin{abstract}
The aim of the article is to present full physiochemical analyses of the mineral water from spring Px- 6 which is used for the treament of patients in the Clinic of Thalassotherapy, Physiotherapy and Rehabilitation at Saints Constantine and Helena resort, the indications for use of that water and the main benefits that may occur after treatment.

Full physico-chemical analyses show significant stability in the composition of the components. Combining physical exercises, electrotherapy, hot packs with lye or other kind of physical factors with balneotherapy is highly effective for the treatment of different disorders. The use of water for prophylaxis, wellness and recreation in healthy people is not excluded. Contraindications are limited.

Though the positive effect of water from spring Px-6 is proven concerning its physico-chemical characteristics and our own experience, more scientific researches should be conducted to increase the evidence of the benefits of this water and its further optimal use for prophylaxis, treatment and wellness.
\end{abstract}

Keywords: physico-chemical characteristics, spring, mineral water, balneotherapy, indications for use

\section{INTRODUCTION}

Taking the waters used to be a popular treatment for a wide range of diseases in classical times. Historical references track spas not only to ancient Romans, but to Sumerian, Egyptian, Greek, Indian and Asian cultures (1). The Greeks preferred baths in fresh water from natural resources, although bath-

\footnotetext{
Address for correspondence:

Evgeniya Petrova Vladeva, $M D, P h D$

Department of Physiotherapy, Rehabilitation,

Thalassotherapy and Occupational Diseases

St. Marina Univesity Hospital of Varna

$1 \mathrm{Hr}$. Smirnenski Blvd

e-mail: jeni.vladeva@gmail.com
}

Received: May 14, 2018

Accepted: June 5, 2018 ing in the sea (thalassotherapy) was also applied. In Homeric times, bathing was primarily used for cleansing and hygienic purposes. By the time of Hippocrates (460-370BC), bathing was considered more than a simple hygienic measure; it was healthy and beneficial for most diseases (2). Influenced by the Greeks, the Romans built their own thermal baths at mineral and thermal springs. Asclepiades (c. 124 BC), a Greek physician who practiced in Rome, started using general hydrotherapy and drinking cures as treatments. He recommended bathing for therapeutic purposes and prevention (2). Galen (AD 131201) also advocated the use of water for the treatment of a variety of diseases (3). With the fall of the Roman Empire and the rise of Christianity, the bathing culture was compromised and bathing was officially prohibited. Faith in cure through religious devotion and praying was regarded as more important than a 
medicinal bath. Around 1800 interest in the bathing culture grew again. Attempts to analyze mineral water were made, aiming at improving its use in medicine, and at preparing mixtures of water identical to those mineral waters famous for their curative properties (4).

Our country is rich in hydromineral resources and annually new springs with a variety of physicochemical characteristicc are discovered (5). There is a great scientific and working knowledge about the treatment and prophylaxis of many diseases through the use of mineral water.

Saints Constantine and Helena is a resort town at the Bulgarian Black Sea coast within a landscaped park $8 \mathrm{~km}$ north of downtown Varna. This is the oldest Black sea resort also known in the past as Druzhba and Varna Resort. The area is a natural terrace over the sea with 10-15 meters altitude. Of main importance for the development of the resort is the presence of 7 mineral springs without analog in Europe. They are low mineralized with high concentration of calcium and magnesium, depth of origin at about $1800-2050$ meters underground and total debit of $175 \mathrm{~L} / \mathrm{s}$. The temperature varies between 30 to 60 degrees for the different springs in the resort $(6,7)$.

Water from spring $P x-6$, which is amongst these 7 springs, is used for the therapeutical purposes of the Clinic of Thalassotherapy, Physiotherapy and Rehabilitation especially at the department of the clinic which is situated on the territory of Hotel Estrea in the resort.

The aim of the article is to present full physicochemical analyses of the mineral water from spring Px-6 which is used for the treament of patients in the Clinic of Thalassotherapy, Physiotherapy and Rehabilitation at Saints Constantine and Helena resort, the indications for use of that water and the main benefits that may occur after treatment.

\section{MATERIAL AND METHODS}

Full physico-chemical analyses of the mineral water from spring Px- 6 were conducted. A literature review was done of the available data for balneotherapy effects and spa treatment use of hydrocarbonicsulphate-sodium-magnesium mineral water. A historical and documentary method for processing the gathered information was used in addition to analysis and data summary.

\section{RESULTS AND DISCUSSION}

Physico-chemical analyses of the mineral water from spring $P x-6$ :

There are different points of view in literature concerning the definition of mineral water. Today the most contemporary definition is that mineral water is natural water with substance and energy or mainly energy, which significantly and in a unique way differs from the local or regional standard. Full physico-chemical analyses of the mineral water from spring Px-6 were conducted at the Medical University of Varna, showing significant stability in the composition of the components. The characteristics of the water did not show significant departure from the norm concerning color, smell and opacity. The temperature is neutral $\left(37.0^{\circ} \pm 0.6\right)$. The Ph level is 7.5 - slightly alkaline, close to neutral. Based on the physico-chemical characteristics the water is with low mineralization $(4.6 \pm 0.2)$ with low hardness (4.4 $\pm 0.1 \mathrm{mg}$ eqv/l).

The mineral content of the water is as follows:

1. Macroelements

- basic anions - $\mathrm{Cl}^{-}, \mathrm{HCO}_{3}^{-}, \mathrm{SO}_{2}{ }^{-}$

- basic cations - $\mathrm{Na}^{+}, \mathrm{K}^{+}, \mathrm{Ca}^{2+}, \mathrm{Mg}^{2+}, \mathrm{Fe}^{3+}$

2. Mesocomponents - $\mathrm{F}^{-}$

3. Microcomponents $-\mathrm{Se}^{4+}$

4. Gases - not found

The interpretation of water analyses determined that this is hydrocarbonic-sulphate-sodiummagnesium water with total mineralization of 4.6 $\mathrm{mmol} \mathrm{H} \mathrm{H}^{+} / \mathrm{l}$.

A significant characteristic of any mineral water is its thermal, oxidation-reducing and radiant energy. For the water from spring - Px-6 this characteristic is as follows:

1. Thermal energy - $\left(37.0^{\circ} \pm 0.6\right)$ - not quite hyperthermal.

2. Oxidation-reducing energy - weakly reducing.

3. Radiant energy - not established.

Indications for use:

Therapy with water has been known for thousands of years. The principle of stimulation, which uses the naturally reactions of the human 
Table. 1. Physico-chemical analyses of the mineral water from spring Px-6

\begin{tabular}{|c|c|c|c|c|}
\hline Index & $\begin{array}{l}\text { Unit of } \\
\text { measurement }\end{array}$ & Result & $\begin{array}{l}\text { Permissible } \\
\text { value }\end{array}$ & $\begin{array}{l}\text { Conditions of } \\
\text { investigation }\end{array}$ \\
\hline Color & degree & 0 & $\begin{array}{l}\text { Without significant } \\
\text { fluctuation }\end{array}$ & $(21 \pm 3)^{\circ} \mathrm{C}$ \\
\hline Smell & degree & 2 & $\begin{array}{l}\text { Without significant } \\
\text { fluctuation }\end{array}$ & $(21 \pm 3)^{\circ} \mathrm{C}$ \\
\hline Opacity & FNU & $0.24 \pm 0.05$ & $\begin{array}{l}\text { Without significant } \\
\text { fluctuation }\end{array}$ & $(21 \pm 3)^{\circ} \mathrm{C}$ \\
\hline Active reaction & $\mathrm{Ph} \mathrm{e}$ & $7.5 \pm 0.1$ & $6.5-9.5$ & $(20.0 \pm 0,6)^{\circ} \mathrm{C}$ \\
\hline Ammonium ion & $\mathrm{mg} / \mathrm{l}$ & $0.18 \pm 0.02$ & 0.50 & $(21 \pm 3)^{\circ} \mathrm{C}$ \\
\hline Ammonia & $\mathrm{mg} / \mathrm{l}$ & $0,24 \pm 0.03$ & - & $(21 \pm 3)^{\circ} \mathrm{C}$ \\
\hline Nitrite & $\mathrm{mg} / \mathrm{l}$ & $<0.05$ & 0.50 & $(21 \pm 3)^{\circ} \mathrm{C}$ \\
\hline Nitrate & $\mathrm{mg} / \mathrm{l}$ & $<3$ & 50 & $(21 \pm 3)^{\circ} \mathrm{C}$ \\
\hline Conductiveness & $\mu \mathrm{S} / \mathrm{sm}$ & $677 \pm 30$ & 2000 & $(20.0 \pm 0,6)^{\circ} \mathrm{C}$ \\
\hline $\mathrm{Ca}^{2+}$ & $\mathrm{mg} / \mathrm{l}$ & $44 \pm 1$ & 150 & $(21 \pm 3)^{\circ} \mathrm{C}$ \\
\hline $\mathrm{Mg}^{2+}$ & $\mathrm{mg} / \mathrm{l}$ & $27 \pm 1$ & 80 & $(21 \pm 3)^{\circ} \mathrm{C}$ \\
\hline Sulphate & $\mathrm{mg} / \mathrm{l}$ & $54 \pm 5$ & 250 & $(21 \pm 3)^{\circ} \mathrm{C}$ \\
\hline Phosphate & $\mathrm{mg} / \mathrm{l}$ & $<0.03$ & 0.50 & $(21 \pm 3)^{\circ} \mathrm{C}$ \\
\hline $\mathrm{Cl}^{-}$ & $\mathrm{mg} / \mathrm{l}$ & $77 \pm 3$ & 250 & $(21 \pm 3)^{\circ} \mathrm{C}$ \\
\hline $\mathrm{Fe}^{3+}$ & $\mu \mathrm{g} / 1$ & $44 \pm 5$ & 200 & $(21 \pm 3)^{\circ} \mathrm{C}$ \\
\hline $\mathrm{Cr}^{+}$ & $\mu g / 1$ & $<10$ & 50 & $(21 \pm 3)^{\circ} \mathrm{C}$ \\
\hline $\mathrm{F}^{+}$ & $\mathrm{mg} / \mathrm{l}$ & $0.50 \pm 0.07$ & 1.5 & $(21 \pm 3)^{\circ} \mathrm{C}$ \\
\hline $\mathrm{Se}^{4+}$ & $\mu g / 1$ & $<1$ & 10 & $(21 \pm 3)^{\circ} \mathrm{C}$ \\
\hline $\mathrm{Na}^{+}$ & $\mathrm{mg} / \mathrm{l}$ & $46 \pm 6$ & 200 & $(21 \pm 3)^{\circ} \mathrm{C}$ \\
\hline $\mathrm{K}^{+}$ & $\mathrm{mg} / \mathrm{l}$ & $<5$ & - & $(21 \pm 3)^{\circ} \mathrm{C}$ \\
\hline Alkalinity & $\mathrm{MmolH}^{+} / 1$ & $4.6 \pm 0.2$ & - & $(21 \pm 3)^{\circ} \mathrm{C}$ \\
\hline Organic carbon & $\mathrm{mg} / \mathrm{l}$ & $9.3 \pm 0.9$ & $\begin{array}{l}\text { Without significant } \\
\text { fluctuation }\end{array}$ & $(21 \pm 3)^{\circ} \mathrm{C}$ \\
\hline $\begin{array}{l}\text { Dissolved sulphide and } \\
\text { uncombined } \mathrm{SO}_{2}^{-}\end{array}$ & $\mathrm{mg} / \mathrm{l}$ & $1.2 \pm 0.1$ & - & $(21 \pm 3)^{\circ} \mathrm{C}$ \\
\hline Hardness & $\mathrm{Mg}$ eqv/l & $4.4 \pm 0.1$ & 12 & $(21 \pm 3)^{\circ} \mathrm{C}$ \\
\hline
\end{tabular}

body, is probably the most ancient curative principle, where the methods physical therapy, balneotherapy and other kinds of resort healing prevail and modern medicine should not ignore it.

The moderate hyperthermality and hardness of the water from spring Px-6, combined with the low mineralization and the specific content of mineral substances and microelements are qualities that allow the use of the water in many different ways of applications and for the treatment and prophylaxis of various types of diseases and conditions.

There are several ways of using mineral water under clinical conditions:

1. external use - bathing in swimming pools and baths;

2. internal use, which affects the metabolic chains;

3. inhalations;

4. lavage. 
In the department of our clinic the external use of mineral water is preferred.

Combining exercises with balneotherapy is highly effective for the treatment of different musculoskeletal disorders (8) and very good results are obtained with treating diseases involving the locomotor and nervous systems. Having in mind the specific characteristics of water from spring Px-6, it can be successfully used for the treatment of certain diseases of the peripheral nervous system, chronic low back pain (9), post-traumatic conditions such as fractures, sprains and also with patients which have undergone postoperative treatment like alloplastic surgery and arthroscopy. Prescribing hydrotherapy treatment to our patients we expect to achieve pain relief, reduction of muscle spasm and increased range of motion, especially by means of underwater exercises.

In the past decades, a large change in the use of mineral water for the treatment of several diseases has taken place in continental Europe. The medical significance of bathing is now acknowledged, especially by many rheumatologists and dermatologists $(10,11)$. Bathing is usually combined with many other treatments, such as physical exercises, hydrotherapy and mud packs (15). In the last decades several randomized controlled trials have studied the effects of balneotherapy in rheumatoid arthritis $(12,13)$ and osteoarthritis $(14,15)$ indicating that hydrotherapy with home exercises may be superior to home exercises alone in the management of patients with general osteoarthrosis (OA) associated with knee OA $(16,17)$. A study with patients suffering from ankylosing spondylitis demonstrated that significant improvements in function, pain, global wellbeing, and morning stiffness were found nine months after balneotherapy (18). Combination of resistive underwater exercises and interferential current therapy is a valuable treatment for patients with juvenile idiopathic arthritis (19). In the department of our Clinic of Hydrotherapy, in most of the cases, it is combined with other kinds of physical factors such as electrotherapy, hot packs with lye or gym exercises. Thus synergistic effects from different by action but similar by result agents are obtained.

The mechanism of action of balneotherapy is based on complex reflex and humoral influences over the human body (20) which provoke distinctive reactions. This is called "stimulation". This principle of stimulation, which uses the natural reaction of the human body, is probably the most ancient curative principle where the methods of physical therapy, balneotherapy and other kinds of resort healing prevail. Usually this is related to the activation of the system hypothalamus-hypophysis-adrenal gland and stimulates the mechanism of adaption to a nonspecific stimulant that takes the human body to a new higher level of reactivity and thus helps the patient to overcome stress and potential illnesses or to fight chronic diseases. This irritating stimulation is a kind of nonspecific reactive regulating therapy which is expressed in a readjustment of the body's reactivity (21).

In balneotherapy, sometimes the desired therapeutic effect does not occur immediately. Days and sometimes weeks are necessary to achieve this effect. Sometimes even a reaction to balneology may occur (22). However, the achieved results are long-lasting, they lead to stable remission of chronic diseases and contribute to the wellbeing of patients.

The use of water for prophylaxis, wellness and recreation in healthy people is not excluded. In this way it becomes a kind of spa treatment, which is based on health promotion and prevention of illnesses. The change in hydrotherapeutic practices includes enriching their range of motion in time. The idea for health prophylaxis reaches higher level which serves as a base for the foundations of the wellness conception. In these cases bathing is usually combined with many other treatments, such as physical exercises, electrotherapy, heat therapy, different kind of eastern practices etc. (3).

The contraindications are limited and include cancer, different kinds of infections, cardiovascular and respiratory diseases in the stage of decompensation and certain skin diseases.

The treatment should be conducted under a physician's control having in mind the complications that may occur after any kind of balneological treatment.

\section{CONCLUSION}

Hydrotherapy and balneotherapy have been known for thousands of years. The principle of stimulation, which uses the natural reactions of the human body, is probably the most ancient curative principle, where the methods of physical therapy, 
balneotherapy and other kinds of resort healing prevail and modern medicine should not ignore it. The moderate hyperthermality and hardness of the water from spring Px-6, combined with its low mineralization and the specific content of mineral substances and microelements, are qualities that allow the use of this water for treatment of diseases of the peripheral nervous system, chronic low back pain, osteoarthritis and after postoperative treatment like alloplastic surgery and arthroscopy.

Combining exercises with balneotherapy is highly effective for the treatment of different musculoskeletal disorders and very good results are obtained in treating diseases involving the locomotor and nervous systems. Bathing is usually combined with many other treatments, such as physical exercises, electrotherapy and mud packs or hot packs with lye. Though the desired therapeutic effect sometimes does not occur immediately and sometimes even a balneology reaction may occur the achieved results are long-lasting, leading to stable remission of chronic diseases and contributing to the wellbeing of patients.

The use of water for prophylaxis, wellness and recreation in healthy people is not excluded. In this way it becomes a kind of spa treatment which is based on health promotion and prevention of illnesses.

Though the positive effect of water from spring Px-6 is proven concerning its physico-chemical characteristics and our own experience, more scientific researches should be conducted for increasing the evidence of the benefits of this water and its further optimal use for prophylaxis, treatment and wellness.

\section{REFERENCES}

1. Johnson EM, Redman BM. SPA: A Comprehensive Introduction. Amer Hotel \& Lodging Assn Educational Institute; 2009.

2. Jackson, R. Waters and spas in the classical world. Med Hist Suppl. 1990; 10:1-13.

3. Routh, H, Bhowmik KR, Parish LC, Witkowski JA. Balneology, mineral water, and spas in historical perspective. Clin Dermatol 14. 1996; 14(6):551-4.

4. Coley, N. Physicians, chemists and the analysis of mineral waters: "the most difficult part of chemistry”. Med Hist Suppl; 1990; 10:56-66.

5. Karakolev D. Osnovi na Balneolechenieto. Sofia: Medicina i Fizkultura; 1984. p. 56-65
6. https://en.wikipedia.org/wiki/Saints_Constantine_ and_Helena,_Bulgaria.(n.d.)

7. Kostadinov D, Karakolev D. Glawni Balneologichni Kurorti. Sofia: Medicina i Fizkultura; 1983

8. Verhagen AP, Cardoso JR, Bierma-Zeinstra SM. Aquatic exercise \& balneotherapy in musculoskeletal conditions. Best Pract Res Clin Rheumatol. 2012; 26(3):335-43. doi: 10.1016/j.berh.2012.05.008

9. Karagülle M, Karagülle MZ. Effectiveness of balneotherapy and spa therapy for the treatment of chronic low back pain: a review on latest evidence. Clin Rheumatol. 2015; 34(2):207-14. doi: 10.1007/ s10067-014-2845-2.

10. Riyaz A, Arakkal FR. Spa therapy in dermatology. Indian J Dermatol Venereol Leprol. 2011; 77(2):128 34. doi: 10.4103/0378-6323.77450.

11. Schlessinger J. Spa dermatology: past, present, and future. Dermatol Clin.2008; 26(3):403-11. doi: 10.1016/j.det.2008.03.006.

12. Franke A, Reiner L, Pratzel HG, Franke T, Resch KL. Long-term efficacy of radon spa therapy in rheumatoid arthritis - a randomized sham-controlled study and follow-up. Rheumatology (Oxford). 2000;39(8):894-902.

13. Roques B, Bouvier CE. Spa therapies, therapeutic education and osteoarthritis. Rev Infirm. 2016; 223:31-2. doi: 10.1016/j.revinf.2016.06.007.

14. Sukenik S, Buskila D, Neumann L, KleinerBaumgarten A, Zimlichman S, Horowitz J. Sulphur bath and mud pack treatment for rheumatoid arthritis at the Dead Sea area. Ann Rheum Dis. 1990; 49(2):99-102.

15. Verhagen AP1, de Vet HC, de Bie RA, Kessels AG, Boers M, Knipschild PG. Balneotherapy for rheumatoid arthritis and osteoarthritis (Cochrane review). Cochrane Database Syst Rev. 2000;(2):CD000518. doi: 10.1002/14651858. CD000518.

16. Forestier R, Genty C, Waller B, Françon A, Desfour $\mathrm{H}$, Rolland C, et al. Crenobalneotherapy (spa therapy) in patients with knee and generalized osteoarthritis: a post-hoc subgroup analysis of a large multicentre randomized trial. Ann Phys Rehabil Med. 2014; 57(4):213-27. doi: 10.1016/j.rehab.2014.03.001.

17. Evcik D, Kavuncu V, Yeter A, Yigit I. The efficacy of balneotherapy and mud-pack therapy in patients with knee osteoarthritis. Joint Bone Spine.2007; 74(1):60-5. doi: 10.1016/j.jbspin.2006.03.009. 
18. van Tubergen A, Landewé $R$, van der Heijde $D$, Hidding A, Wolter N, Asscher M, et al . Combined spa-exercise therapy is effective in patients with ankylosing spondylitis: a randomized controlled trial. Arthritis Rheum. 2001; 45, 430-8.

19. Elnaggar RK, Elshafey MA. Effects of combined resistive underwater exercises and interferential current therapy in patients with juvenile idiopathic arthritis: A randomized controlled trial. Am J Phys Med Rehabil., 2016; 95(2):96-102.

20. Stamatov S. Balneology and Health Tourism. Sofia: Medicina i Fizkultura; 1984.

21. Dajkky A. Balneology. Sofia: Medicina i Fizkultura; 1977 (in Bulgarian).

22. Stamatov S, Karakolev D, Cvetkova L. Clinical Health-Resort Science. Sofia: Medicina i Fizkultura; 1990 (in Bulgarian). 